\title{
Aprendizaje en semiología radiológica para Tecnólogos en Radiología de la Fundación Universitaria del Área Andina, mediante una herramienta informática
}

\author{
A. Cruz Medina', VA. Henao Arias'; JS. Loaiza Marín'; \\ D. López Domínguez'; M. Pulgarín Montes'. \\ Docentes Asesores: AM . Rincón-Hurtado²; C. Gallego-Londoño
}

RESUMEN La Semiología es una materia compleja que se enseña desde diversas metodologías, lo cual la hace de alto esfuerzo académico para los estudiantes que la requieren en el desarrollo de su actividad.

Se ha encontrado que la literatura sobre Semiología Radiológica está dirigida al Médico Radiólogo, lo cual genera un inconveniente para el Tecnólogo en Radiología debido al enfoque, extensión y profundidad de los temas encaminados al diagnóstico y el tratamiento.

El uso de las Tecnologías de Información y Comunicación (TIC), facilitan a los docentes la enseñanza de la semiología, y de esta manera el aprendizaje de esta para los estudiantes, simplificando así la comprensión de la información y el acceso a la misma.

Por medio de esta investigación se plantea que, a partir de la implementación de la herramienta informática se producirán diferencias significativas entre el postest y el pretest (intra-grupos) y los sujetos de un grupo experimental.

Radiología;

PALABRAS Aprendizaje;

CLAVE Informática;

Diagnóstico

1 Estudiantes de V semestre del Programa de Tecnología en Radiología e Imágenes Diagnósticas de la Fundación Universitaria del Área Andina. Semillero GIRA.

2 Docente Asesor metodológico.

3 Docente Asesora temática. 


\section{Learning in radiological semiology for Radiology Technologists of the Fundación Universitaria del Área Andina, using a computer tool}

ABSTRACT Semiology is a complex subject that is taught from different methodologies, which makes it a great academic effort for students who require it in the development of their activity.

It has been found that the literature on Radiological Semiology is addressed to the Radiology Physician, which creates a drawback for the Radiology Technologist due to the focus, Extension and depth of topics aimed at diagnosis and treatment.

The use of Information and Communication Technologies (ICT), facilitate to teachers the teaching of semiology, and in this way the learning of this for students, thereby simplifying the understanding of and access to information.

Through this research it is proposed that, from the implementation of the computer tool, there will be significant differences between the postest and the pretest (intra-groups) and the subjects of an experimental group.

\section{Radiology;}

Learning;

Computing;

Diagnosis 


\section{INTRODUCCIÓN}

La incorporación de las Tecnologías de Información y Comunicación (TIC) en la educación, es una postura novedosa. Existen establecimientos educativos que fomentan el uso de las TIC como complemento para reforzar la educación tradicional (1). Algunos docentes las ven como facilitadoras de su labor, otros les dan gran valor, pues en la sociedad actual los jóvenes viven su día a día compartiendo con ellas, y argumentan que con su cohabitación frecuente mejoran el aprendizaje por su estímulo motivacional (2).

El uso de las TIC en la educación tiene relación tanto en el aprendizaje como con la enseñanza, porque en el ambiente educativo se da gran importancia a la organización de los temas para que motiven al estudiante, y permitan integrar los conocimientos, logrando aprendizajes profundos (3-6). En esencia, un enfoque detallado se relaciona con una motivación propia e interés en el contenido de la tarea; el estudiante la personaliza, le da significado, la relaciona con sus ideas y experiencias previas. Cuando los alumnos emplean una orientación profunda de aprendizaje, producen sus ideas con mayor espontaneidad, dan explicaciones más elaboradas, hacen preguntas dirigidas a encontrar explicaciones o que resuelvan discrepancias en el conocimiento y su lenguaje será más preciso, logrando con esto mejorar su proceso de formación.

Los artículos leídos serían la base para iniciar el proceso correspondiente a la elaboración de dicha herramienta informática, siendo un gran aporte en la investigación y una guía para llegar a la obtención de resultados en esta investigación, proporcionando conocimientos y herramientas que permitan resolver algunas de las situaciones que puedan presentarse; plantean estrategias de cómo llevar a cabo una herramienta informática de gran utilidad y eficacia, en cómo los profesores podrían mejorar o apoyar sus técnicas de enseñanza y facilitar así el aprendizaje a los estudiantes, ya que en ocasiones la escasa implementación de los recursos tecnológicos en los centros de educación, se debe a la falta de accesibilidad y existencia de los mismos.

Estos artículos son un apoyo para saber cómo estructurar contenidos dotados de información: desde el punto de vista de lo estructural y de navegación, hasta el diseño; que tengan suficiente flexibilidad para que los estudiantes accedan de manera sencilla a la información, y tomar las acciones necesarias con el fin de reforzar sus conocimientos acordes a sus necesidades.

En la formación del Tecnólogo en Radiología e Imágenes Diagnósticas, el aprendizaje requiere de un apoyo visual permanente. Desde el ciclo inicial de la carrera, la apreciación visual y la interpretación de lo observado son elementos presentes en la evolución de atribución del método clínico para el ejercicio profesional, y en el área de la semiología radiológica con enfoque al Tecnólogo en Radiología, se identifican los problemas que se representan y relacionan en el siguiente esquema: 


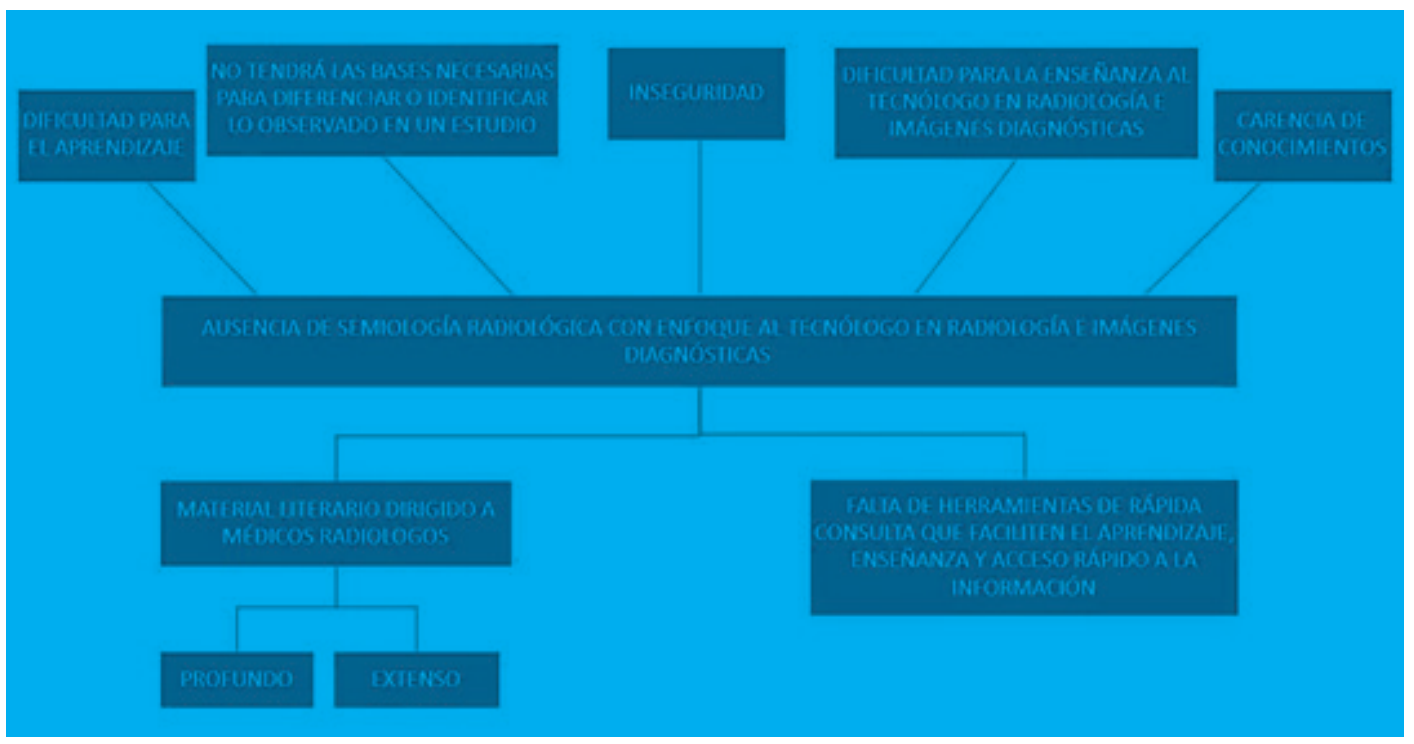

Figura 1.

Esquema identificación de problemas

Con base en lo anterior, se identifica la necesidad de desarrollar e implementar una herramienta informática que permita el aprendizaje en semiología radiológica para estudiantes de Tecnología en Radiología, de la Fundación Universitaria del Área Andina en el año 2020.

\section{MATERIALES Y MÉTODOS}

Población y muestra: en esta investigación participarán 2 grupos de estudiantes de Tecnología en Radiología e Imágenes Diagnósticas, de la Fundación Universitaria del Área Andina, con matrícula vigente en el segundo semestre de 2019.

El diseño muestral será de carácter no probabilístico y por conveniencia, donde se seleccionarán aquellos estudiantes que cumplan con los criterios de inclusión y exclusión.

Tipo de estudio: estudio cuasi experimental, con dos grupos: uno experimental y otro de control no equivalente (puesto que los grupos no serán asignados al azar). El estudio se desarrollará en 3 fases, así:

Fase I: identificación de la herramienta informática. En esta fase se requiere elaborar una revisión de literatura que permita seleccionar los contenidos a partir de las necesidades, tomando como base los elementos propios de la materia de semiología y de las tecnologías de la información, que favorecerán el desarrollo de diferentes tipos de procesos: observar, seleccionar, comparar, entre otros, $\mathrm{y}$, por ende, diferentes formas de agrupar la información. 
Fase II: desarrollo de la herramienta informática. En esta fase se requiere elaborar la herramienta informática, en las plataformas virtuales escogidas para tal fin.

Fase III: se llevarán a cabo pruebas evaluativas que analicen la eficacia docente y de aprendizaje de los procedimientos informáticos elaborados. Además, se recogerán sus impresiones y críticas, que permitan estudiar las ventajas que aporta este sistema respecto a las técnicas de formación tradicionales.

Plan de análisis: se llevará a cabo un análisis estadístico de las variables a medir en el estudio. Se calcularán los estadísticos descriptivos, media $(\mathrm{M})$ y desviación típica (DT) para cada uno de los ítems evaluados, mediante un cuestionario elaborado por el grupo investigador que será calificado por expertos. Se realizarán las pertinentes pruebas de normalidad y homocedasticidad para asegurar la homogeneidad de la varianza.

Se realizará un análisis de ANOVA 2x2 de medidas repetidas, que permita la comparación del prestest con el postest, para analizar los efectos del programa de intervención. Para todo ello se empleará el paquete estadístico SPSS v. 22.

\section{RESULTADOS}

Entre los resultados que se pretenden obtener de esta investigación, puesto que aún se encuentra en curso, son el de conseguir una mayor claridad de la semiología al momento de estudiarla en la carrera de Tecnología en Radiología e Imágenes Diagnósticas, induciendo a los tecnólogos y a los estudiantes a la utilización de la herramienta tecnológica como una ventaja para acceder a la información. También se espera lograr un cambio significativo de la sociedad ante la percepción de la semiología enfocada en los radiólogos 
REFERENCIAS 1. Telesalud Universidad de Caldas. Educación virtual. [Citado 2010 Sep. 2]. Disponible en URL:http://telesalud.ucaldas.edu.co

2. Delgado M, Solano A. Estrategias Didácticas Creativas en Entornos Virtuales para el Aprendizaje. Actualidades Investigativas en Educación [serie en línea] 2009 [citado 2010 Sep. 6]; 9(2):1-21. Disponible en URL: http://revista.inie. ucr.ac.cr

3. Casado R. El aprovechamiento de las tecnologías de la información y la comunicación (TIC) para la creación de redes de aprendizaje colaborativo: La experiencia de Telefónica de España. [Citado 2010 Sep. 3]. Disponible en URL: http://cvc.cervantes.es/obref/formacion_virtual/tele_aprendizaje/casado.htm

4. González M. NETCampus, una solución integral para la formación a distancia a través de sistemas virtuales. Online educa Madrid 2000. [Citado 2010 Sep. 8]. Disponible en URL: http://cvc.cervantes.es/obref/formacion_virtual/ metodologia/arechabaleta.htm

5. Noa L, Gil J. El ABC de las nuevas tecnologías. Experiencias sobre un curso en la web. [Citado 2010 Sep. 3]. Disponible en URL: http://cvc.cervantes.es/ obref/formacion_virtual/metodologia/noa.htm

6. Barth L, Mariño S, Bonomo D. Construcción de un entorno virtual para el aprendizaje de la Embriología General Humana. Com Cient y Tecn 2004; 36:155-74. 


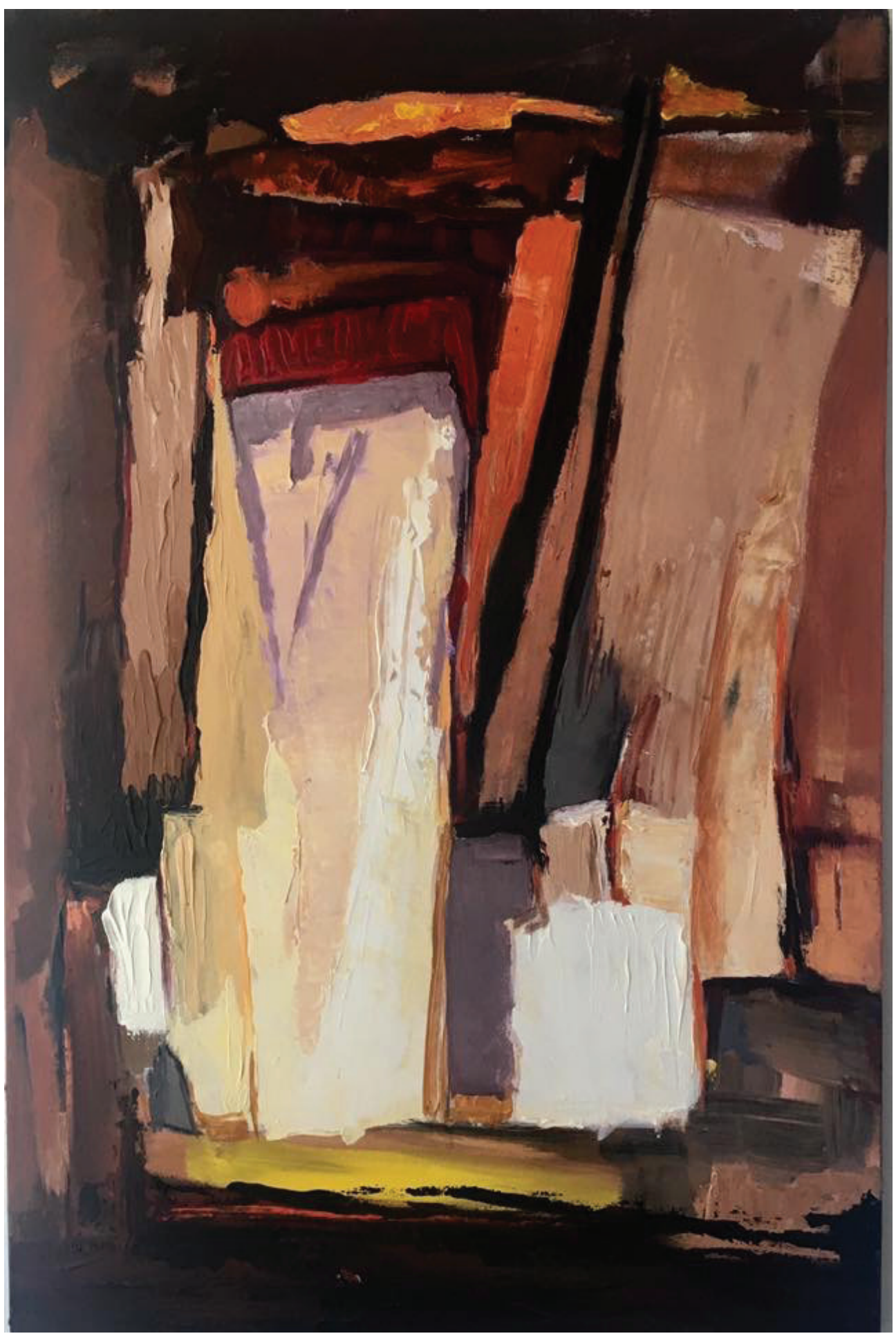

Acrílico sobre lienzo. "De la serie Puertas”, Virginia Aristizábal Parra. 